\title{
Results of nonendoscopic endonasal dacryocystorhinostomy
}

This article was published in the following Dove Press journal:

Clinical Ophthalmology

10 August 2012

Number of times this article has been viewed

\section{Passorn Preechawai}

Department of Ophthalmology, Faculty of Medicine, Prince of Songkla University, Hat Yai, Songkhla, Thailand
Correspondence: Passorn Preechawai Department of Ophthalmology, Faculty of Medicine, Prince of Songkla University, Hat Yai, Songkhla, 90110 Thailand

Tel +6674451380

Fax +6674429619

Email ppassorn@yahoo.com
Background: Surgical scarring on the face and disrupted anatomy in the medial canthal area following external dacryocystorhinostomy (DCR) can be avoided by an endonasal approach. This study examined the outcome of direct visualization endonasal DCR, performed by young surgeons and residents.

Methods: A retrospective case series of 75 consecutive endonasal DCRs performed under direct visualization from July 2002 to July 2004 were reviewed. Surgery was performed by surgeons and residents who had received no special training in the procedure. Full success was defined as no symptoms of tearing after surgery and anatomical patency with fluorescein flow on nasal endoscopy or patency to lacrimal syringing. Partial success was defined as a tearing decrease compared with prior to surgery and with anatomical patency, and failure was defined as no significant improvement in persistent tearing. The average follow-up duration was $26.83 \pm 16.26$ (range 6-55) months.

Results: Seventy-five DCRs were performed on 63 patients (four male, 59 female) of mean age $49.44 \pm 16.63$ (range $21-85$ ) years. The surgery was successful in 54/75 eyes (72\%), 37/54 eyes $(68.5 \%)$, and $30 / 42$ eyes $(71.4 \%)$ at 6,12 , and 24 months, respectively. Partial success was achieved in $13 / 75(17.3 \%), 9 / 54(16.7 \%)$, and $9 / 42(21.4 \%)$, and the failure rates were $10.7 \%$, $14.8 \%$, and $7.1 \%$ at 6,12 , and 24 months, respectively. The overall functional success with this technique was $74.7 \%$ and the overall anatomical patency was $92.0 \%$. There were no serious complications arising from the surgery; three minor complications were documented, ie, an incorrectly placed silicone tube in the lower canaliculus, tube prolapse, and postoperative bleeding which needed nasal packing and eventually a developed retention cyst in the nasal cavity.

Conclusion: Endonasal DCR under direct visualization is a simple technique with minimal complications and a low learning curve, without the necessity for expensive instruments.

Keywords: endonasal DCR, dacryocystorhinostomy, lacrimal surgery, nasolacrimal duct obstruction

\section{Introduction}

Dacryocystorhinostomy (DCR) is the treatment of choice for patients with acquired nasolacrimal duct obstruction. External DCR was first described by Toti in $1904{ }^{1}$ External DCR is performed in a standardized fashion whereby a skin incision is made, the lacrimal and maxillary bones are removed, and the sac mucosa is connected to the nasal mucosa. The success rate with this surgery is in the range of $80 \%-95 \%$, with the major risks being wound complications (scar, infection, ectropion, or disruption of the medial canthal ligament) and bleeding from the nose. ${ }^{2-4}$ The endonasal approach was first attempted in 1893 by Caldwell, ${ }^{5}$ but was limited by poor visibility 
of the endonasal anatomy during surgery, and was only rarely used. However, since the 1990s, with the introduction of modern techniques and equipment, attention has turned to an endonasal approach for nasolacrimal duct obstruction, both for primary surgery or to revise failed cases. ${ }^{6,7}$ The endonasal approach has a number of advantages, notably a reduced incidence of surgical scarring, skin infection, and ectropion, or disruption of the medial canthal ligament. However, there are several disadvantages of the endonasal approach to DCR, such as a higher learning curve and surgical skills compared with an external approach, and the need for expensive instrumentation. ${ }^{8}$

There are several techniques used for endonasal DCR, and the instruments for visualization may be different between endoscopic ${ }^{9-11}$ and direct visualization, ${ }^{12}$ with different surgical instruments used for removal of bones, most commonly a surgical drill, diamond-blurring, rongeur, hammer-chisel, radiofrequency, or laser-assisted ablation. ${ }^{4-9-11,13-17}$ The success rates for these methods have been in the range of $60 \%-99 \%$, depending on various factors, including the surgical skills of the surgeon. ${ }^{10-22}$ The disadvantages of these new endonasal techniques are that they require expensive instruments and higher surgical skills. ${ }^{8}$ This study was undertaken to evaluate the outcome of endonasal DCR procedures in our institution performed by surgeons under direct visualization and without prior training.

\section{Materials and methods}

This study was a retrospective case series review of patients aged at least 18 years who underwent surgery for acquired nasolacrimal duct obstruction by endonasal DCR under direct visualization at Songklanagarind Hospital from July 2002 to July 2004. Prior to surgery all patients underwent a comprehensive ophthalmic examination along with irrigation of the nasolacrimal drainage system. Patients were excluded if the tearing was due to canalicular obstruction or lower eyelid malposition, or if the postoperative follow-up period was less than 6 months. The surgeries were performed by a surgeon who was experienced but not trained specifically in endonasal DCR and by first-year to third-year residents. All patients were informed that a team of surgeons would do the operation. Institutional review board approval was obtained for the study prior to its inception.

Patients were examined at one week postoperatively, then at one, 3, 6, and 12 months, and yearly thereafter. The silicone stent was removed at 6 weeks after the operation. Full success was defined as no tearing, ie, patients did not report additional episodes of tearing postoperatively, with anatomical patency by fluorescein flow on nasal endoscopy or patency to lacrimal syringing. Partial success was defined as a tearing decrease compared with prior to surgery and with anatomical patency. Failure was defined as persistent tearing, inability to irrigate the lacrimal system, and no fluorescein dye in the intranasal surgical site on nasal endoscopy. The statistical analysis was analyzed by percentages.

\section{Surgical technique}

All surgeries were performed under general anesthesia. Nasal packing was done with $1 \%$ ephedrine-soaked gauze. Patients with an abnormal nasal cavity that obscured visualization of the surgical field were excluded from the study and were converted to external DCR. The light pipe was threaded through the upper canaliculus until it touched the bony medial wall of the lacrimal sac. Lidocaine with epinephrine was infiltrated along the lateral wall of the nose at the proposed osteotomy site, which was identified first using a vitrectomy light pipe. The surgeon sat at the side of the patient opposite to the nostril involved, and directly viewed the transillumination target using a nasal speculum with a $5 \mathrm{~cm}$ long blade. A headlight was not necessary because the vitrectomy light pipe provided sufficient illumination. Before performing the operation, the nasal cavity was examined for any abnormal anatomy, such as nasal septum deviation or nasal polyps; those could make surgery more difficult to perform or represent a pathology of nasolacrimal duct obstruction. A sickle knife was used to incise an elliptical shape in the nasal mucosa approximately $8-10 \mathrm{~mm}$ in length at the axilla of the middle turbinate. A Freer periosteal elevator (model 474000, Karl Storz, Tuttlingen, Germany) was used to separate the mucosa from the underlying bone, and this mucosa was peeled away by ethmoid forceps. The lacrimal bone was then broken with the Freer elevator, and the lacrimal and frontal processes of the maxillary bone were removed using a Kerrison rongeur (models 662102, 662103, 662121, Karl Storz). The opening in the bone was widened until the surgeon could no longer feel any bone with the light pipe. At this stage, the surgeon would see the light pipe lighter, because there was only lacrimal sac mucosa remaining. The assistant then tented the lacrimal sac mucosa with the light pipe and the surgeon incised a posteriorly-based U-shaped oval flap to the osteotomy margins using the sickle knife. Blakesley forceps (Karl Storz) were used to tear off this flap. The surgeons explored the area with the light pipe, and if she or he felt any resistance from the bone or mucosa, additional bone or lacrimal sac mucosa was removed superiorly until they felt 
there were no obstructions. The final step was to pass the silicone tube through both the upper and lower canaliculi and a knot was tied in the nasal cavity. Following surgery, the patient was given topical combined steroid and antibiotic eye drops four times a day and steroid nasal spray two times a day for 4 weeks postoperatively.

\section{Results}

There were 75 endonasal DCR performed under direct visualization on 63 patients (four male, 59 female) during the review period. Two patients were excluded from the study because of nasal polyps that obstructed the surgical view and another had severe septal deviation. Both patients were converted to external DCR without correcting nasal anatomy before surgery. Their average age was $49.44 \pm 16.63$ (range 21-85) years. The surgical results are shown in Table 1 . The surgeries were successful in $54 / 75$ eyes $(72 \%)$, $37 / 54$ eyes $(68.5 \%)$, and $30 / 42$ eyes $(71.4 \%)$ at 6,12 , and 24 months, respectively. Partial success was achieved in 13/75 (17.3\%), 9/54 (16.7\%), and 9/42 (21.4\%) eyes at 6, 12, and 24 months, and the surgeries were considered failures in $10.7 \%, 14.8 \%$, and $7.1 \%$ at 6,12 , and 24 months, respectively. The overall functional success rate was $74.7 \%$ and the overall anatomical patency was $92.0 \%$.

Three patients developed complications. One patient had an incorrectly placed silicone tube in the lower canaliculus instead of the punctum, but the operation was successful. The tube prolapsed in another patient, and another had postoperative bleeding and needed nasal packing, and eventually developed a retention cyst in the nasal cavity. Both of these cases failed to achieve operative success.

Three patients who had failed results showed fibrosis at the nasal mucosa. Two of these cases underwent reoperation using the same technique, with one successful outcome and one failure. Thirty-three patients were lost to follow-up at 24 months and this may explain why the success rate at 24 months looked to be higher than at 12 months.

\section{Discussion}

Although the endonasal DCR procedure was first described in $1893,{ }^{5}$ well before the external approach, ${ }^{1}$ limitations in visualization of the nasal cavity proved to present too many obstacles for surgery to be successful, and the standard procedure for most of the last century was external DCR. With modern equipment and techniques, the internal approach was revisited in 1990 by Massaro et $\mathrm{al}^{7}$ and since then, many surgeons have adopted endonasal DCR due to its several advantages, notably no surgical scarring, limited invasiveness leading to improve preservation of the pump function of the orbicularis oculi muscle, a shorter operative time, and less intraoperative bleeding. ${ }^{23,24}$ External DCR has some disadvantages, including facial scar formation and poor lacrimal pump from interruption of medial canthal anatomy and the orbicularis oculi muscles, ${ }^{25}$ and is limited in patients who have acute dacryocystitis with abscess formation. ${ }^{26}$ However, there are still some disadvantages associated with the endonasal technique, which are the relatively smaller opening between the lacrimal sac and nasal cavity so that surgery has a somewhat higher recurrence rate, a higher cost for specialized equipment, and it is a more difficult procedure to learn. ${ }^{23,24}$ These factors of a steeper learning curve and the more difficult technique required to create the opening successfully tend to lead to a slightly lower success rate. ${ }^{16}$

In this study, we did not use an endoscope to reduce the cost of instrumentation, there was no learning curve in endoscopic skills, and all of the surgeons who performed the surgery had never done this procedure previously. The author was the leading surgeon and had just finished residency training at the time the surgeries were started, and the others were first-year to third-year residents who did their surgeries under supervision of the author. The functional success rate in this study was $74.7 \%$, which was less than that reported by Dolman ${ }^{12}$ and by Razavi et $\mathrm{al}^{27}(89.1 \%$ and $96 \%$, respectively). There are several factors contributing to why inexperienced surgeons could have a lower success rate than more experienced surgeons, ${ }^{28}$ including difficulty in

Table I Outcome for nonendoscopic endonasal dacryocystorhinostomy

\begin{tabular}{|c|c|c|c|c|c|c|c|}
\hline \multirow[t]{3}{*}{ Outcome } & \multicolumn{7}{|c|}{ Postoperative time } \\
\hline & \multicolumn{2}{|c|}{6 months } & \multicolumn{2}{|c|}{12 months } & \multicolumn{2}{|c|}{24 months } & \multirow{2}{*}{$\frac{\text { Overall ( }>6 \text { months) }}{\%}$} \\
\hline & $\mathbf{n}$ & $\%$ & $\mathbf{n}$ & $\%$ & $\mathbf{n}$ & $\%$ & \\
\hline Full success & $54 / 75$ & 72 & $37 / 54$ & 68.5 & $30 / 42$ & 71.4 & 74.7 \\
\hline Partial success & $13 / 75$ & 17.3 & $9 / 54$ & 16.7 & $9 / 42$ & 21.4 & 26.7 \\
\hline Anatomical success & $67 / 75$ & 89.3 & $46 / 54$ & 85.2 & $39 / 42$ & 92.9 & 92.0 \\
\hline Failure & $8 / 75$ & 10.7 & $8 / 54$ & 14.8 & $3 / 42$ & 7.1 & 10.3 \\
\hline
\end{tabular}


manipulation of the instruments in the nasal cavity, ${ }^{8}$ although this technique is less difficult than using an endoscope. Making the openings in the nasal mucosa, bone, and lacrimal sac is more difficult, because the surgical field is smaller than when using an external approach. Understanding the limitations in manipulation of the instruments within the nasal cavity can improve the surgical skills needed to make the opening wider, which is the key to improving functional success. A study by Onerci et $\mathrm{al}^{29}$ found that the surgical success of endoscopic DCR in the hands of experienced surgeons was $94.4 \%$, while inexperienced surgeons had a success rate of only $58 \%$. This study showed that inexperienced surgeons had a functional success rate of $74.7 \%$ and an anatomical success rate of $92 \%$. This implies that the learning curve for endoscopic DCR is much higher than for nonendoscopic endonasal DCR. This study did not do subgroup analysis by comparing the first and second year, because residents rotated to the oculoplastic unit for 1-2 months, once a year.

In this study, the success rate at 24 months $(30 / 42,71.4 \%)$ was higher than at 12 months $(37 / 54,68.5 \%)$ and could be explained by the number of patients at 24 months being lower than at 12 months because of loss of 12 patients to follow-up. We used silicone tubing in all patients because our hypothesis that when we removed both lacrimal and nasal flaps, the wound healed by secondary intention, the silicone tube would work similarly to a stent to prevent closure. However, a meta-analysis of DCR with or without silicone intubation ${ }^{30}$ showed no benefit of silicone intubation in primary DCR. In other situations, such as previous acute dacryocystitis, poor flap creation, revision surgery, excessive bleeding, inflammatory disease, and small sacs, silicone intubation might be of benefit. ${ }^{30}$

Regarding improved surgical success, two factors need to be addressed. Some surgeons have suggested that the size of the osteotomy may be more important, whereas others have emphasized the importance of the osteotomy location. ${ }^{31}$ The endonasal approach may allow for more control when customizing osteotomy placement. ${ }^{32-34}$ Our study used a vitrectomy light pipe to identify the lacrimal sac and osteotomy site and at the end of surgery to recheck the site of osteotomy to see if there was any resistance of bone or mucosa, and if so, additional bone and/or lacrimal sac mucosa were removed superiorly until no obstructions were felt. This technique helps to increase the success rate. Another factor to increase the success rate is using mitomycin $\mathrm{C}$ to delay wound healing or prevent scarring at the opening. Several authors have used mitomycin C. ${ }^{35,36}$ A study by Dolmetsch et al ${ }^{35}$ showed improvement in the outcome of nonlaser endonasal DCR to
$95 \%$ with adjunctive mitomycin C. This study did not use mitomycin $\mathrm{C}$ to improve the outcome, but it may be used in a future study.

There were no serious complications in this study, whilst previous studies have reported tear periorbita, medial rectus injury, ${ }^{11}$ leakage of cerebrospinal fluid, ${ }^{6}$ and orbital fat herniation. ${ }^{37-39}$ The complications found in endonasal DCR are different from those commonly seen with the external approach because, when doing an internal procedure, the instruments are pointed towards the orbit, increasing the risk of this type of injury. In our series, we used a vitrectomy light pipe to create a surgical landmark and indicate the safe area, so that the risk of injury to the orbit, globe, or meninges was greatly diminished. Complications in external DCR are more frequent but less severe compared with the endonasal approach, and include wound infection, bruising, scarring, and punctual ectropion. ${ }^{12,40}$

The major disadvantage of this technique is visualization. Therefore, if a tumor in the lacrimal sac is suspected, this technique might not be a good option. However, it is not normally suspected, because the incidence of significant pathology in the lacrimal sac in clinically suspected acquired nasolacrimal duct obstruction is low. ${ }^{41-43}$ Most tumors in the lacrimal sac are seen in patients with known pre-existing disease, or when a grossly abnormal lacrimal sac is revealed during surgery. This limitation can lead to misdiagnosis of an unsuspected lacrimal sac tumor.

The clinical implications of this study are that this technique is simple to perform, and has a minimal complication rate and a low learning curve, with no need for expensive instruments. The success rate is acceptable and might be enhanced by using mitomycin $\mathrm{C}$.

\section{Disclosure}

This paper was presented in part at the combined annual meeting of the Oculoplastic Association of India and Asia-Pacific Society of Ophthalmic Plastic and Reconstructive Surgery, Hyderabad, India, December 14-16, 2007. The author has no financial interest in any of the equipment mentioned in this article.

\section{References}

1. Toti A. Nuovo metodo conservatore di cura radicale delle suppurazioni croniche del sacco lacrimale (dacriocistorinostomia). Clin Mod Firenze. 1904;10:385-387. Italian.

2. Tarbet KJ, Custer PL. External dacryocystorhinostomy. Surgical success, patient satisfaction and economic cost. Ophthalmology. 1995;102:1065-1070.

3. Hanna IT, Powrie S, Rose GE. Open lacrimal surgery: a comparison of admission outcome and complications after planned day case or inpatient management. Br J Ophthalmol. 1998;82:392-396. 
4. Hartikainen J, Grenman R, Puukka P, Seppa H. Prospective randomized comparison of external dacryocystorhinostomy and endonasal laser dacryocystorhinostomy. Ophthalmology. 1998;105:1106-1113.

5. Caldwell GW. Two new operations for obstruction of the nasal duct, with preservation of the canaliculi. Am J Ophthalmol. 1893;10:189-192.

6. McDonogh M, Meiring JH. Endoscopic transnasal dacryocystorhinostomy. J Laryngol Otol. 1989;103:585-587.

7. Massaro BM, Gonnering RS, Harris GJ. Endonasal laser dacryocystorhinostomy. A new approach to nasolacrimal duct obstruction. Arch Ophthalmol. 1990;108:1172-1176.

8. Watkins LM, Janfaza P, Rubin PAD. The evolution of endonasal dacryocystorhinostomy. Surv Ophthalmol. 2003;48:73-84.

9. Whittet HB, Shun-Shin GA, Awdry P. Functional endoscopic transnasal dacryocystorhinostomy. Eye. 1993;7:545-549.

10. Tsirbas A, Wormald PJ. Endonasal dacryocystorhinostomy with mucosal flaps. Am J Ophthalmol. 2003;135:76-83.

11. Tsirbas A, Wormald PJ. Mechanical endonasal dacryocystorhinostomy with mucosal flaps. Br J Ophthalmol. 2003;87:43-47.

12. Dolman PJ. Comparison of external dacryocystorhinostomy with nonlaser endonasal dacryocystorhinostomy. Ophthalmology. 2003;110:78-84

13. Henson RD, Henson RG Jr, Cruz HL Jr, Camara JG. Use of diode laser with intraoperative mitomycin $\mathrm{C}$ in endocanalicular laser dacryocystorhinostomy. Ophthal Plast Reconstr Surg. 2007;23:134-137.

14. Javate RM, Campomanes BS Jr, Co ND, et al. The endoscope and the radiofrequency unit in DCR surgery. Ophthal Plast Reconstr Surg. 1995;11:54-58.

15. Hehar SS, Jones NS, Sadiq SA, Downes RN. Endoscopic holmium: YAG laser dacryocystorhinostomy - safe and effective as a day-case procedure. J Laryngol Otol. 1997;111:1056-1059.

16. Gonnering RS, Lyon DB, Fisher JC. Endoscopic laser-assisted lacrimal surgery. Am J Ophthalmol. 1991;111:152-157.

17. Cokkeser Y, Evereklioglu C, Er H. Comparative external versus endoscopic dacryocystorhinostomy: result in 115 patients (130 eyes). Otolaryngol Head Neck Surg. 2000;123:488-491.

18. Moore WMH, Bentley CR, Olver JM. Functional and anatomical results after two types of endoscopic endonasal dacryocystorhinostomy, surgical and holmium laser. Ophthalmology. 2002;109:1575-1582.

19. Mantynen J, Yoshisuga M, Rautianene M. Results of dacryocystorhinostomy in 96 patients. Acta Otolaryngol. 1997;529:187-189.

20. Sadiq SA, Ohrlich S, Jones NS, Downes RN. Endonasal laser dacryocystorhinostomy - medium term results. $\mathrm{Br} J$ Ophthalmol. 1997;81:1089-1092.

21. Szubin L, Papageorge A, Sacks E. Endonasal laser-assisted dacryocystorhinostomy. Am J Rhinol. 1999;13:371-374.

22. Boush GA, Lemke BN, Dortzbach RK. Results of endonasal laserassisted dacryocystorhinostomy. Ophthalmology. 1994;101:955-959.

23. Anijeet D, Dolan L, MacEwen CJ. Endonasal versus external dacryocystorhinostomy for nasolacrimal duct obstruction. Cochrane Database Syst Rev. 2011;19:CD007097.

24. Lee DW, Chai CH, Loon SC. Primary external dacryocystorhinostomy versus primary endonasal dacryocystorhinostomy: a review. Clin Experiment Ophthalmol. 2010;38:418-426.

25. Wormald PJ, Tsirbas A. Investigation and endoscopic treatment for functional and anatomical obstruction of the nasolacrimal duct system. Clin Otolaryngol Allied Sci. 2004;29:352-356.

Clinical Ophthalmology

\section{Publish your work in this journal}

Clinical Ophthalmology is an international, peer-reviewed journal covering all subspecialties within ophthalmology. Key topics include: Optometry; Visual science; Pharmacology and drug therapy in eye diseases; Basic Sciences; Primary and Secondary eye care; Patient Safety and Quality of Care Improvements. This journal is indexed on Submit your manuscript here: http://www.dovepress.com/clinical-ophthalmology-journa
26. Lee TS, Woog JJ. Endonasal dacryocystorhinostomy in the primary treatment of acute dacryocystitis with abscess formation. Ophthal Plast Recostr Surg. 2001;17:180-183.

27. Razavi ME, Eslampoor A, Noorollahian M, O’Donnell A, Beigi B. Non-endoscopic endonasal dacryocystorhinostomy: technique, indications and results. Orbit. 2009;28:1-6.

28. Mirza S, Al-Barmani A, Douglas SA, Bearn MA, Robson AK. A retrospective comparison of endonasal KTP laser dacryocystorhinostomy versus external dacryocystorhinostomy. Clin Otolaryngol Allied Sci. 2002;27:347-351.

29. Onerci M, Orhan M, Ogretmenoglu O, Irkec M. Long-term results and reasons for failure of intranasal endoscopic dacryocystorhinostomy. Acta Otolaryngol. 2000;120:319-322.

30. Feng YF, Cai JQ, Zhang JY, Han XH. A meta-analysis of primary dacryocystorhinostomy with and without silicone intubation. Can J Ophthalmol. 2011;46:521-527.

31. Lee S, Yen MT. Laser-assisted dacryocystorhinostomy: a viable treatment option? Curr Opin Ophthalmol. 2011;22:413-418.

32. Goldberg RA. Endonasal dacryocystorhinostomy: is it really less successful? Arch Ophthalmol. 2004;122:108-110.

33. Hong JE, Hatton MP, Leib ML, Fay AM. Endocanalicular laser dacryocystorhinostomy analysis of 118 consecutive surgeries. Ophthalmology. 2005;112:1629-1633.

34. Plaza G, Betere F, Nogueira A. Transcanalicular dacryocystorhinostomy with diode laser: long-term results. Ophthal Plast Reconstr Surg. 2007;23:179-182.

35. Dolmetsch AM, Gallon MA, Holds JB. Nonlaser endoscopic endonasal dacryocystorhinostomy with adjunctive mitomycin $\mathrm{C}$ in children. Ophthal Plast Reconstr Surg. 2008;24:390-393.

36. Camara JG, Bengzon AU, Henson RD. The safety and efficacy of mitomycin $\mathrm{C}$ in endonasal endoscopic laser-assisted dacryocystorhinostomy. Ophthal Plast Reconstr Surg. 2000;16:114-118.

37. Kong YT, Kim TI, Kong BW. A report of 131 cases of endoscopic laser lacrimal surgery. Ophthalmology. 1994;101:1793-1800.

38. Sprekelsen MB, Barberan MT. Endoscopic dacryocystorhinostomy: surgical technique and results. Laryngoscope. 1996;106:187-189.

39. Sham CL, Van Hasselt CA. Endoscopic terminal dacryocystorhinostomy. Laryngoscope. 2000;110:1045-1049.

40. Karim R, Ghabrial R, Lynch T, Tang B. A comparison of external and endoscopic endonasal dacryocystorhinostomy for acquired nasolacrimal duct obstruction. Clin Ophthalmol. 2011;5:979-989.

41. Tucker N, Chow D, Stockl F, Codere F, Burnier M. Clinically suspected primary acquired nasolacrimal duct obstruction: clinicopathologic review of 150 patients. Ophthalmology. 1997;104:1882-1886.

42. Merkonidis C, Brewis C, Yung M, Nussbaumer M. Is routine biopsy of the lacrimal sac indicated at dacryocystorhinostomy? A prospective study and literature review. Br J Ophthalmol. 2005;89:1589-1591.

43. Bernardini FP, Moin M, Kersten RC, Reeves D, Kulwin DR. Routine histopathologic evaluation of the lacrimal sac during dacryocystorhinostomy: how useful is it? Ophthalmology. 2002;109: $1214-1224$

\section{Dovepress}

PubMed Central and CAS, and is the official journal of The Society of Clinical Ophthalmology (SCO). The manuscript management system is completely online and includes a very quick and fair peer-review system, which is all easy to use. Visit http://www.dovepress.com/ testimonials.php to read real quotes from published authors. 